\title{
Desenho Universal para a Aprendizagem aplicado à promoção da educação inclusiva: uma revisão sistemática
}

\author{
Célia Regina Vitaliano ${ }^{1}$ \\ Jacqueline Lidiane de Souza Prais ${ }^{2}$ \\ Katiane Pereira dos Santos ${ }^{3}$
}

\begin{abstract}
RESUMO
Este artigo tem o objetivo de analisar a aplicação do Desenho Universal para a Aprendizagem (DUA) na promoção da educação inclusiva em produções científicas brasileiras. Para tanto, adotou como encaminhamento metodológico as etapas da revisão sistemática para uma busca em diversos sites científicos que resultaram na identificação de 24 estudos sobre o tema. A leitura exaustiva das obras analisadas permitiu a organização dos dados de análise em cinco categorias: 1) elaboração de material didático, 2) formação docente inicial e/ou continuada, 3) planejamento de ensino, 4) articulação com outro conceito e 5) prática pedagógica. As análises desenvolvidas evidenciaram a natureza das produções científicas que abordam a perspectiva do DUA no contexto da inclusão educacional. Além disso, os resultados forneceram subsídios teóricos e práticos para a compreensão das possibilidades de implementação do DUA para favorecer o aprimoramento da educação inclusiva nos diferentes níveis e modalidades de ensino.
\end{abstract}

PALAVRAS-CHAVE: Inclusão educacional. Prática pedagógica. Desenho Universal para a Aprendizagem (DUA).

\footnotetext{
${ }^{1}$ Doutora em Educação. Universidade Estadual de Londrina (UEL), Paraná, Brasil. https://orcid.org/0000-00028757-4204.reginavitaliano@gmail.com.

2 Mestre em ensino. Universidade Estadual de Londrina (UEL), Paraná, Brasil. https://orcid.org/0000-0002-36587021.jacqueline_lidiane@hotmail.com.

3 Especialista em Educação Especial. Universidade Estadual de Londrina (UEL), Paraná, Brasil. https://orcid.org/0000-0002-0023-2819. kati1841@hotmail.com.
} 
Universal Design for Learning applied to the promotion of inclusive education: a systematic review

\begin{abstract}
The aim of this article was to analyze the application of the Universal Design for Learning (UDL) in the promotion of inclusive education through a systematic review of Brazilian scientific production. For this, it carried out a search in several scientific sites that resulted in the identification of 24 academic productions on the subject. The exhaustive reading of the analyzed works allowed the organization of the data of analysis in five categories: 1) preparation of didactic material, 2) initial and/or continuous teacher training, 3) education planning, 4) articulation with another concept and 5) pedagogical practice. The developed analyze evidenced the nature of the scientific productions that address the perspective of the UDL in the context of educational inclusion. Furthermore, the results provided theoretical and practical support for the understanding of the possibilities of implementation of the UDL to favor the improvement of inclusive education in the different levels and modalities of teaching.
\end{abstract}

KEYWORDS: Educational inclusion. Pedagogical practice. Universal Design for Learning

\title{
Introdução
}

A educação inclusiva consiste em um movimento de luta pelo direito de todos à educação e representa um desafio para o contexto das escolas regulares (RODRIGUES, 2006). Dentre os aspectos necessários para sua efetivação está a prática pedagógica adequada as necessidades de aprendizagem dos alunos (OMOTE, 2003).

De acordo com Mantoan (2015, p. 28) a educação inclusiva é aquela que "propõe um modo de organização do sistema educacional que considera 
as necessidades de todos os alunos, estruturado em função dessas necessidades".

Partindo desse pressuspoto, pesquisadores norte-americamos (MEYER, ROSE; GORDON, 2014) estruturaram e difundiram uma proposta denominada de Universal Design for Lerning (UDL), a qual adotamos a tradução para Desenho Universal para a Aprendizagem (DUA). Essa abordagem começou a ser sistematizada a partir da década de 1990 e as pesquisas relacionadas a essa perspectiva são recentes (PRAIS, 2016).

Para construção do DUA, Meyer, Rose e Gordon (2002) consideraram as inquietações difundidas pelos conceitos de Desenho Universal e acessibilidade na área da arquitetura, visando problematizar a necessidade de se considerar tais aspectos na e para a aprendizagem.

Por conseguinte, o DUA amplia o conceito de acessibilidade a espaços, objetos e ferramentas para apresentar um desenho didático que norteia o professor para a organização do ensino em uma perspectiva inclusiva que perpassa pela flexibilidade do currículo e acesso à aprendizagem (MEYER; ROSE; GORDON, 2002; CAST, 2011).

Esta abordagem tem como ponto de partida que o docente identifique as necessidades de aprendizagem na turma, busque recursos e procedimentos didáticos que possam melhorar o desempenho dos alunos e promover uma ação educativa pautada na e para a aprendizagem do conteúdo (PRAIS, 2017; ZERBATO, 2018).

O DUA estabelece como princípios norteadores: i) possibilitar múltiplas formas de apresentação do conteúdo, ii) proporcionar vários modos de ação e expressão do conteúdo pelo aluno e, iii) promover a participação, interesse e engajamento na realização das atividades pedagógicas (CAST, 2011) que devem ser traduzidos como objetivos na elaboração do planejamento de ensino em uma perspectiva inclusiva.

Essa proposta didática tem por finalidade minimizar as barreiras para aprendizagem buscando aprimorar o processo de ensino a partir de 
procedimentos, recursos e atividades que considerem as características individuais dos estudantes (PACHECO, 2017).

Percebemos que os princípios norteadores do DUA envolvem a capacidade de planejar e avaliar a própria prática pedagógica, pelo professor no contexto do ensino regular, durante o desenvolvimento e a realização das atividades pedagógicas com intenções inclusivas (CAST, 2011; PRAIS, 2016; ZERBATO, 2018).

Assim, Nunes e Madureira (2015, p. 133) explicam que a perspectiva do DUA está articulada com uma abordagem curricular, pois "[...] procura minimizar as barreiras à aprendizagem e maximizar o sucesso de todos os alunos e, nessa medida, exige que o professor seja capaz de começar por analisar as limitações na gestão do currículo, em vez de sublinhar as limitações dos alunos".

Cabe esclarecer que a proposta do DUA não apresenta um encaminhamento metodológico rígido, fechado e inflexível, mas sim apresenta subsídios para que o professor possa (re)planejar buscando alternativas coerentes com o perfil e necessidades dos estudantes de sua turma (ZERBATO; MENDES, 2018). Desse modo, ao incorporar os conhecimentos da educação inclsiva poderá empregar os princípios do DUA em qualquer conteúdo de ensino, pois estará traçando intenções claras e coerência, especialmente sobre "o que, para que e como" ensinar os conteúdos aos alunos (PRAIS, 2016).

Com base nisso, surgiu nosso interesse em identificar no contexto brasileiro a influência desses conhecimentos para a promocação da prática pedagógica inclusiva.

Nessa direção, este artigo tem por questão problematizadora: de que maneira a perspectiva do Desenho Universal para a Aprendizagem relacionada à inclusão educacional tem sido contemplada nas produções científicas brasileiras?

Para responder a essa pergunta, empregamos como metodologia de pesquisa a denominada revisão sistemática, conforme Senra e Lourenço 
(2016). Tivemos como objetivo central caracterizar as produções científicas que abordam o DUA e a inclusão educacional dispostas no sistema de busca de dados do Google Acadêmico, e nas bases de dados do Catálogo de Teses e dissertações da Capes, da Biblioteca Digital Brasileira de Teses e dissertações (BDTD) e do Portal de Periódicos da Capes.

Diante da relevância desse tema de pesquisa e do interesse em desvelar as características e contribuições das pesquisas já desenvolvidas sobre o DUA no contexto da educação inclusiva, apresentamos neste artigo uma revisão sistemática.

\section{Método}

As revisões sistemáticas metodologicamente organizadas suprem a necessidade de identificar as possibilidades de investigações desenvolvidas e as lacunas a serem preenchidas em relação a um determinado tema. (SENRA; LOURENÇO, 2016). Assim, as revisões sistemáticas dão suporte teórico e metodológico para desencadear novas pesquisas, caracterizar o cenário do tema e esclarecer impasses, resultados e considerações relevantes para a compreensão de determinado tema.

Como metodologia de pesquisa esse procedimento consiste em uma "[...] uma revisão da literatura científica, com objetivo pontual, que utiliza uma metodologia padrão para encontrar, avaliar e interpretar estudos relevantes [...]" (SENRA; LOURENÇO, 2016, p. 176). Os mesmos autores indicam que a revisão sistemática deve ser realizada a partir de dez passos que foram adotados e são apresentados a seguir juntamente com os encaminhamentos que tomamos em nossa pesquisa. Somado a isso, a discussão dos dados foi ancorada na análise qualitativa.

Conforme o delineamento apresentado por Senra e Lourenço (2016), estabelecemos as seguintes etapas:

Etapa 1: Delimitamos como tematica desta pesquisa "Desenho Universal para a Aprendizagem aplicado à promoção da educação inclusiva”. 
Etapa 2: Como demarcação de intervalo temporal foi delimitada a pesquisa de produções científicas dos últimos dez anos.

Etapa 3: Definimos como base para coleta de dados o banco de informações do Google Acadêmico, do Catálogo de Teses e dissertações da Capes, da Biblioteca Digital Brasileira de Teses e Dissertações (BDTD) e do Portal de Periódicos da Capes. Convém explicar que a quantidade de bases escolhidas diz respeito a possibilidade de identificação de um maior número de pesquisa e tipos de publicações.

Etapa 4: Determinamos como descritores de busca: Desenho Universal para a Aprendizagem (DUA) e as variáveis - da, para, na, de -, e em inglês, Universal Design for Learning (UDL) em todas as bases de dados, associada a palavra-chave "inclusão".

A partir desse levantamento, identificamos 63 produções científicas para serem examinadas, conforme detalhamos no Quadro 1.

Quadro 1 - Levantamento preliminar das produções científicas nas bases de dados

\begin{tabular}{|l|c|c|}
\hline \multicolumn{1}{|c|}{ Bases de dados } & $\begin{array}{c}\text { Busca pelo termo } \\
\text { "Desenho Universal } \\
\text { para a Aprendizagem" } \\
\text { e as variáveis - "da, } \\
\text { para, na, de" }\end{array}$ & $\begin{array}{c}\text { Busca pelo termo } \\
\text { "Universal Design for } \\
\text { Learning" }\end{array}$ \\
\hline Google Acadêmico4 & 55 & Não alterou o resultado \\
\hline $\begin{array}{l}\text { Catálogo de Teses e dissertação } \\
\text { da Capes }\end{array}$ & 3 & 5 \\
\hline $\begin{array}{l}\text { Biblioteca Digital Brasileira de } \\
\text { Teses e Dissertações (BDTD) }\end{array}$ & 1 & 2 \\
\hline Portal de Periódicos da Capes & 1 & 1 \\
\hline Total: 68 resultados & 60 & 8 \\
\hline
\end{tabular}

Fonte: Autores (2018)

Etapa 5: Analisamos as produções científicas encontradas na busca a partir de critérios estabelecidos para inclusão e exclusão dos textos

\footnotetext{
${ }^{4}$ Cabe explicar que o Google Acacadêmico consiste em um sistema de busca de produções científicas desenvolvidas no âmbito acadêmico.
} 
relevantes e irrelevantes à temática da pesquisa. Desse modo, priorizamos as produções científicas que atendiam os seguintes critérios: 1. pesquisas concluídas publicadas em idioma português; 2. busca por frase exata do descritor; 3. exclusão de arquivos duplicados ou triplicados na mesma base ou em banco de dados diferentes.

Ao examinar as 68 produções científicas selecionadas previamente nas bases de dados escolhidas, nove delas apareceram em mais de uma base de dados, os arquivos duplicados foram excluídos. Dando continuidade a análise das pesquisas, empregamos a exclusão de 22 dos arquivos. Cabe detalhar que a exclusão se deu pelos critérios: três por se tratar de artigo de revisão sistemática, dez pesquisas de Portugal, uma resenha de livro, duas acesso online não disponível, uma localizado apenas o resumo da pesquisa, bem como, cinco por se tratar de pesquisas ainda não concluídas.

Etapa 6: Nessa etapa fizemos uma leitura analítica dos estudos encontrados evidenciando os diretamente relacionados com a abordagem do DUA e a inclusão educacional, temática central de interesse nesta revisão sistemática. Assim, 13 produções científicas foram excluídas por não atenderem a esse critério de seleção, sendo: 12 por apenas mencionar o Desenho Universal para a Aprendizagem nas considerações finais ou título de uma referência utilizada e uma por não apresentar o termo exato ou não se tratar da perspectiva do Desenho Universal para a Aprendizagem (DUA).

Desse modo, do universo de 68 produções científicas encontradas, 44 delas foram excluídas, restando 24 produções que compuseram o corpo de análise.

Etapa 7: Nessa etapa catalogamos as produções científicas selecionadas.

Etapa 8: Na oitava etapa, avaliamos e sintetizamos de maneira quantitativa os resultados atingidos buscando compreender o número de pesquisas relevantes sobre o assunto, autor(es) e ano de publicação, tipos de publicações encontradas e o conteúdo abordado nos textos. 
Etapa 9: Concomitantemente, na nona etapa, realizamos uma avaliação e síntese qualitativa para integração dos resultados e possíveis intervenções do fenômeno de interesse buscando categorizar as pesquisas pela forma de abordagem do tema desta revisão sistemática.

De tal modo, por meio da leitura analítica dos trabalhos, constatamos que os pesquisadores tinham objetivos diversos ao abordar a perspectiva do DUA. Com base nesse aprofundamento, foi possível classificar as pesquisas encontradas em cinco categorias, a saber: 1) elaboração de material didático, 2) formação docente (inicial e/ou continuada), 3) planejamento de ensino, 4) articulação com outro conceito e 5) prática pedagógica. A seguir, no Quadro 2, apresentamos a organização das produções científicas em suas respectivas categorias.

Quadro 2 - Organização das produções científicas selecionadas

\begin{tabular}{|c|c|c|c|c|}
\hline Categorias & Tese & Dissertação & $\begin{array}{l}\text { Artigo publicado } \\
\text { em revista }\end{array}$ & $\begin{array}{c}\text { Texto } \\
\text { completo } \\
\text { publicado em } \\
\text { anais de } \\
\text { evento }\end{array}$ \\
\hline $\begin{array}{c}\text { Elaboração de } \\
\text { material } \\
\text { didático }\end{array}$ & $\begin{array}{l}\text { Sondermann } \\
(2014) \\
\text { Santos (2016) }\end{array}$ & $\begin{array}{l}\text { Tizioto (2013) } \\
\text { Costa (2016) } \\
\text { Kranz (2011) }\end{array}$ & $\begin{array}{l}\text { Bastos (2016) } \\
\text { Lemos, Bernardi e } \\
\text { Dal-Forno (2016) }\end{array}$ & $\begin{array}{l}\text { Santos } \\
\text { Fernandes } \\
(2017)\end{array}$ \\
\hline $\begin{array}{c}\text { Formação } \\
\text { docente inicial } \\
\text { e/ou } \\
\text { continuada }\end{array}$ & Zerbato (2018) & Prais (2016) & $\begin{array}{l}\text { Pletsch, Souza e } \\
\text { Orleans (2017) } \\
\text { Linderman, Bastos } \\
\text { e Roman (2017) } \\
\text { Prais e Rosa (2017) } \\
\text { Vilaronga, Mendes e } \\
\text { Zerbato (2016) } \\
\text { Ricardo, Saço e } \\
\text { Ferreira (2017) } \\
\text { Prais e Rosa (2016) }\end{array}$ & - \\
\hline $\begin{array}{l}\text { Planejamento } \\
\text { de ensino }\end{array}$ & 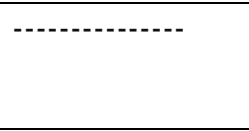 & - & $\begin{array}{l}\text { Prais e Rosa (2016) } \\
\text { Zerbato e Mendes } \\
(2018)\end{array}$ & Prais (2017) \\
\hline $\begin{array}{l}\text { Articulação } \\
\text { com outro } \\
\text { conceito } \\
\end{array}$ & - & $\begin{array}{l}\text { Ricardo } \\
(2017)\end{array}$ & $\begin{array}{l}\text { Calegari, Silva } \\
\text { Silva }(2014)\end{array}$ & 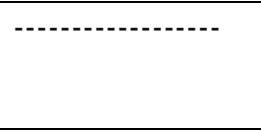 \\
\hline $\begin{array}{c}\text { Prática } \\
\text { pedagógica }\end{array}$ & 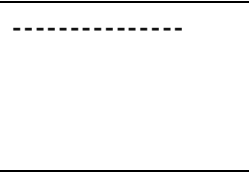 & $\begin{array}{l}\text { Pacheco } \\
\text { (2017) } \\
\text { Roquejani } \\
\text { (2018) } \\
\end{array}$ & $\begin{array}{l}\text { Cruz e Nascimento } \\
(2018)\end{array}$ & 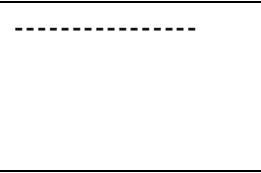 \\
\hline Total & 3 & 7 & 12 & 2 \\
\hline
\end{tabular}


Fonte: Autores (2018)

Etapa 10: Por fim, na décima e última etapa, retomamos a pergunta que desencadeou a revisão sistemática visando o exame de evidências nos estudos agrupados, bem como, a necessidade de novos estudos relacionados à prática pedagógica na educação inclusiva.

Tomando como base a categorização feita a partir dos conteúdos abordados nas investigações, dedicamos a próxima seção para a apresentação da análise dos estudos.

\section{Resultados e discussão}

A análise das 24 produções científicas nos permitiu identificar sete tipos de pesquisas construídas pelos autores: qualitativa descritiva (três), experimental (cinco), viés colaborativo (cinco), intervenção pedagógica (duas), pesquisa-ação (duas), análise documental (duas) e exploratória (cinco). Não julgamos a terminologia e os encaminhamentos metodológicos adotados pelas pesquisas, apenas identificamos como seus autores denominaram o tipo de pesquisa que desenvolveram frente ao tema de investigação.

Com base nos conteúdos abordados nas pesquisas, identificamos a seguir os principais resultados que evidenciaram a perspectiva do DUA para a promoção da educação inclusiva.

\section{a. Elaboração de material didático}

Os oito estudos selecionados nesta primeira categoria empregaram os princípios do DUA na elaboração de material didático. Destacamos que em cinco delas, (TIZIOTO, 2013; SONDERMANN, 2014; SANTOS, 2016; LEMOS; BERNARDI; DAL-FORNO, 2016; SANTOS; FERNANDES, 2017), o material diz respeito a organização de recursos didáticos mais inclusivos 
na modalidade de Educação a Distância. E as pesquisas de Costa (2016), Kranz (2011) e Bastos (2016) tratam do desenvolvimento de recursos didáticos visando satisfazer as necessidades de aprendizagem dos alunos na perspectiva inclusiva.

De acordo com Tiziotto (2013), a partir dos princípios do DUA, houve avanços nos índices de auto eficácia para a aprendizagem, de motivação, de participação e de desenvolvimento das atividades propostas pelo material didático criado e aplicado. Segundo o autor, as quatro propostas didáticas contidas no material didático elaborado possibilitaram que alunos com Necessidades Educacionais Especiais (NEE) pudessem ter acesso a vários recursos permitindo acompanhar a aula e as atividades. Além disso, a aplicação da perspectiva do DUA contribuiu para o acesso adaptado dos recursos didáticos, para o atendimento das necessidades de aprendizagem de alunos com deficiência, o que demonstrou ser uma opção potencialmente viável, sustentável e inclusiva.

$\mathrm{Na}$ pesquisa de Sondermann (2014), a abordagem do DUA foi utilizada como suporte para as ações-reflexões do Design Educacional de um curso na modalidade a distância, em um dos grupos focais realizados na pesquisa, a fim de adotar uma perspectiva inclusiva. A autora supracitada afirma que os resultados obtidos trouxeram contribuições teóricas e práticas para a formação docente e para o trabalho colaborativo.

$\mathrm{Na}$ produção científica publicada por Santos (2016), o DUA foi utilizado como embasamento para o redesign do Ambiente Virtual de Aprendizagem (AVA) e das atividades destinadas a um curso de noções básicas de Educação Financeira, chamado Estudo Piloto à nove participantes com NEE. De acordo com o autor, os Cenários para Investigação propostos no curso contribuíram para o desenvolvimento da matemática e as argumentações utilizadas nas interações nos fóruns de discussão apresentaram criticidade, demonstrnado apropriação dos procedimentos para realizar cálculos matemáticos em decisões financeiras. 
Lemes, Bernardi e Dal Forno (2016), utilizaram os princípios do DUA como base para a construção de espaços virtuais apresentando um guia de diretrizes de acessibilidade, que foi elaborado para o apoio de professores na elaboração de suas disciplinas ou cursos. Os mesmos autores concluíram que o guia pode ser considerado atrativo e motivador aos professores, auxiliando-os de forma mais interativa e funcional no desenvolvimento de seus cursos no Moodle, na adaptação do material para acesso dos alunos com deficiência visual.

Já Santos e Fernandes (2016), apoiados nos princípios e diretrizes do DUA, criaram um ambiente virtual interativo de aprendizagem, no qual usuários com NEE puderam participar de discussões de forma cooperativa, utilizando os recursos de interação disponibilizados em um AVA. Estes autores concluíram que o DUA possibilita minimizar as dificuldades enfrentadas na formação docente para inclusão, bem como, atende às necessidades formativas e práticas para a busca da aprendizagem dos alunos no contexto da inclusão educacional. Os mesmos acreditam que um espaço virtual só poderá ser considerado acessível quando qualquer pessoa tiver acesso ao seu conteúdo com a mesma eficácia.

Costa (2016) utilizou a base do DUA somado ao Design Instrucional e Inteligências Múltiplas para avaliar a interação e a qualidade dos materiais educacionais utilizados por alunos no contexto regular de ensino. A partir dos resultados, a autora constatou que os materiais de ensino e de aprendizagem são as principais ferramentas utilizadas pelos professores, sendo destacados a utilização adequada do material didático, a flexibilização e a personalização dos mesmos. Além disso, considerou relevante, a motivação despertada por estes materiais de ensino, bem como, a presença de elementos que explorem o uso dos órgãos dos sentidos e a promoção de desafios.

Bastos (2016), discutiu os procedimentos e os cuidados necessários para a construção e a adequação de recursos pedagógicos para o ensino de Química a alunos com NEE. Nessa pesquisa, o DUA serviu como base para 
elaboração de uma Tabela Periódica que foi utilizada como recurso na Disciplina Química em uma turma do $1^{\circ}$ Ano do Ensino Médio. A autora supracitada concluiu que as adaptações e proposições realizadas, como forma alternativa ao ensino da tabela periódica, alcançou sucesso e demonstra que a inclusão na escola comum é possível, desde que respeitadas as características dos aprendizes e mobilizados os recursos pedagógicos adequados.

Kranz (2011), fez a análise da utilização de jogos com regras no trabalho com Educação Matemática em classes regulares inclusivas. Neste estudo, a autora propôs a ressignificação de materiais e a mediação pedagógica com base no DUA para a utilização de jogos com regras no trabalho com Educação Matemática. A mesma ressaltou que esse tipo de jogo, se envolver todos os alunos em meio a um clima de participação, interação, problematização e diálogo, pode ser meio para a promoção de novas aprendizagens. Entretanto, constatou em seus resultados, que a utilização dos jogos de regras são utilizados em um contexto que compreende a deficiência como individual e alunos com NEE nem sempre são incluídos no jogo por serem considerados incapazes. Além disso, destacou que pensar a utilização dos jogos de regras no ensino Matemática a partir dos princípios do DUA demonstra a necessidade (re)significar o acesso à aprendizagem dos alunos com NEE a partir da organização das atividades feitas e propostas pelos professores em sala de aula.

Percebemos nesta categoria que o DUA auxiliou no processo de elaboração e na análise de todos os recursos (virtuais ou concretos) expostos. Bem como, os princípios dessa perspectiva possibilitou a reflexão sobre o uso de recursos didáticos na educação inclusiva. Da mesma forma, observamos que os autores buscaram no DUA elementos que os oportunizaram orientar/conscientizar professores sobre a importância do uso de métodos e de recursos adequados às necessidades dos alunos para a promoção de um processo voltado a aprendizagem de todos. 


\section{b. Formação docente inicial e/ou continuada}

Nessa categoria, foram contempladas oito pesquisas que abordaram o DUA na formação de professores inicial e/ou continuada para a inclusão.

Com o intuito de avaliar uma formação colaborativa sobre o DUA, as pesquisas de Vilaronga, Mendes e Zerbato (2016), e Zerbato (2018) demonstrou que pensar as atividades pedagógicas é um dos elementos necessário para a efetivação da inclusão educacional. Vilaronga, Mendes e Zerbato (2016) salienta que o DUA pode ser um aliado do trabalho colaborativo para o favorecimento da inclusão escolar. Zerbato (2018) evidencia que o DUA e o trabalho colaborativo se convergem em um objetivo comum: a construção de práticas pedagógicas acessíveis para a escolarização de todos em sala de aula do ensino comum, por meio da parceria entre professor de ensino comum e Educação Especial e/ou outros profissionais especializados.

Prais e Rosa (2016), analisam aspectos da formação do professor para uma educação inclusiva e constataram que o DUA é uma alternativa para suprir e minimizar as dificuldades enfrentadas na formação docente para inclusão. Os autores ainda defendem que os princípios do DUA correspondem às necessidades formativas e a prática pedagógica dos docentes no contexto da inclusão educacional.

Prais (2016) apresentou em sua dissertação as análises feitas a partir da aplicação de uma Unidade Didática proposta, tendo o DUA como base, em um Curso de Extensão. Segunda a autora, a ação didática formativa realizada melhorou o processo formativo das licenciandas tendo em vista as aprendizagens dos princípios do DUA demonstradas pelas atividades e pelos planos de aula elaborados pelas participantes da pesquisa.

A partir de um recorte da pesquisa Prais e Rosa (2017) constataram que o curso aprimorou a formação dos licenciandos em Pedagogia no que se refere ao planejamento de atividades pedagógicas em uma perspectiva inclusiva. Os autores afirmam que o DUA ofereceu as licenciandas subsídios 
teóricos e práticos para minimizar suas dúvidas com relação ao processo de inclusão dos alunos público-alvo da Educação Especial, bem como, suas dificuldades no que diz respeito a organização da atividade de ensino.

Lindermann, Bastos e Roman (2017) utilizaram o DUA como subsídio teórico para a elaboração de materiais pedagógicos no ensino de Química e na instrumentalização do licenciando para produzirem seus planejamentos. Os autores destacaram que, a partir da intervenção pedagógica desenvolvida no estágio, a atividade de planejamento pelos estudantes subsidiada pelo DUA, possibilitou que os licenciandos aplicassem os subsídios teóricos apropriados, organizassem atividades em uma perspectiva inclusiva e percebessem as adequações necessários no processo de ensino para satisfazer as necessidades de aprendizagem dos alunos no contexto da inclusão educacional.

Pletsch, Souza e Orleans (2017), destacaram em sua pesquisa o uso de práticas diversificadas e currículos flexíveis, ao discutir o estatuto da tecnologia no processo de escolarização de alunos com deficiência intelectual, tendo como fundamento o conceito de diferenciação e o DUA. Tais autores concluíram que a falta de conhecimento dos docentes sobre os processos de escolarização de pessoas com deficiência não possibilitou que eles refletissem sobre ações que favoreçam a práxis pedagógica. Do mesmo modo, observaram a transformação no que diz respeito ao discurso (sobre a prática curricular com alunos com deficiência intelectual) dos participantes ao longo de um curso formativo, a partir do qual eles passaram identificar possibilidades do aluno se desenvolver por meio de mediações pedagógicas voltadas a diferenciação curricular.

Por fim, Ricardo, Saço e Ferreira (2017) discutiram a educação inclusiva no ensino superior apontanto as legislações sobre acessibilidade e inclusão nas Universidades e Instituições de Ensino. Destacaram que o DUA pode ser utilizado como suporte teórico aos professores em sua prática pedagógica, na elaboração do currículo e dos recursos didáticos. Concluíram que o DUA: contribui para o ato de pensar em soluções individualizadas e 
inovadoras ao ser aplicado na concepção de flexibilidade inserida no currículo, dá apoio aos docentes na melhoria do acesso ao conhecimento e à aprendizagem dentro da sala de aula e apresenta ferramentas de suporte que simplificam o conteúdo.

Nessa categoria vimos que o DUA foi utilizado como subsídio em processos de formação docente objetivando fazer com que os participantes das pesquisa refletissem sobre o ato de planejar e desenvolvessem estratégias mais acessíveis para favorecer a participação e aprendizagem de todos os alunos nas atividades pedagógicas. Além disso, percebemos que professores ao longo do processo de formação proposto se perceberam como peças fundamentais no processo de ensino de alunos com NEE, bem como, passaram a acreditar que o ato de aprender é possível a todos alunos, a depender principalmente da postura e da prática do professor.

\section{c. Planejamento de ensino}

Esta categoria contempla três pesquisas que destacaram as contribuições do DUA em relação ao planejamento do professor.

As pesquisas de Prais e Rosa (2016), Prais (2017) apresentam uma ficha de avaliação com base nos princípios do DUA voltada ao auxílio do professor para a elaboração do planejamento e avaliação das atividades propostas em uma perspectiva inclusiva. Prais e Rosa (2016) indicam que o uso desse material didático possibilita nortear a previsão e a projeção de ações mais concretas com vista à promoção da educação incusiva. E Prais (2017) complementa afirmando que a ficha de avaliação potencializa qualitativamente a aprendizagem dos alunos satisfazendo suas necessidades educacionais.

Do mesmo modo, Zerbato e Mendes (2018) discutem a proposta do DUA enfatizando a necessidade de se reduzir o uso de adequações personalizadas do ensino, passando para o planejamento dos conteúdos para turma toda. Nessa premissa, destacam como alternativa o uso do DUA como 
base para o Planejamento do professor e o trabalho colaborativo para a construção de práticas pedagógicas inclusivas.

Essa categoria apresentou propostas instrumentais e atitudinais com base no DUA para o planejamento do professor. Identificamos que os autores buscaram alternativas para auxiliar o professor no processo de organização de atividades inclusivas, sem desconsiderar o contexto de sua sala de aula, as exigências quanto ao planejamento de ensino e o currículo vigente.

\section{d. Articulação com outro conceito}

Elencamos nesta categoria duas pesquisas que relacionaram o DUA a outra perspectiva.

Calegari, Silva e Silva (2014), relacionaram o DUA ao Design Instrucional (DI). Os autores destacaram que se tratam de perspectivas complementares, que, por sua vez, trabalham no objetivo da remoção de barreiras para acesso ao currículo.

Já Ricardo (2017), realizou a identificação dos objetivos e das ações desenvolvidas pelos núcleos de acessibilidade presentes em Universidades Federais participantes do Programa INCLUIR, para compará-los à relatos de estudantes com deficiências. A partir dos resultados, discutiu como a Tecnologia Assistiva (TA) e o DUA poderiam auxiliar em uma proposta de mudança curricular para o desenvolvimento de uma educação heterogênea. A autora concluiu que a política pública de inclusão é incoerente em relação ao processo de inclusão. Tal como Ricardo (2017) analisa que as Universidades estão construindo uma rede de núcleos de acessibilidade apenas para a pessoa com deficiência, deixando de atender as especifidades de outros alunos que também necessitam de adequações e de apoios pedagógicos para sua efetiva inclusão no processo educativo. Além disso, constatou que o DUA e a TA são exemplos de boas práticas de acessibilidade 
no processo de aprendizagem, pois visam a minimização de barreiras entre a atividade organizada e a realização da tarefa pelo aluno.

Em síntese, nessa categoria os autores discutiram a pratica da inclusão nos ambientes de ensinos pesquisados. Essas análises oportunizaram problematizar sobre as políticas públicas, os currículos vigentes e se as práticas educativas se aproximam ou não de uma ação pedagógica inclusiva satisfatória. Somado a isso, percebemos que os princípios do DUA trouxe o direcionamento para que sejam realizadas as devidas adequações.

\section{e. Prática pedagógica}

Nessa última categoria, três pesquisas abordaram a aplicação do DUA na prática pedagógica no contexto regular de ensino.

Pacheco (2017) elaborou e aplicou uma sequência didática com base nos princípios do DUA para a abordagem do Conteúdo "Sistema Respiratório" em uma turma de Educação de Jovens e Adultos que continha alunos com NEE. Após a intervenção pedagógica, a autora supracitada concluiu que o DUA colaborou para o ensino de Ciência e que os alunos responderam cognitivamente melhor nas atividades baseadas no princípio que visa proporcionar modos múltiplos de auto envolvimento. Por sua vez, a implementação dos princípios do DUA na prática pedagógica favoreceu a promoção da cooperação e da participação entre os alunos. Pacheco (2017) demonstra a necessidade de reorganização do currículo e do processo de ensino aos alunos com NEE, bem como, que o DUA possibilita interpretar quais e como os conteúdos podem ser trabalhados de maneira adequada.

Cruz e Nascimento (2018) também promoveram intervenção pedagógica em uma turma da educação básica na qual trabalharam o uso da tecnologia na escolarização de dois estudantes com Transtorno do Expectro Autismo (TEA). As atividades desenvolvidas com os alunos foram realizadas a partir da utilização do computador, tendo como base os 
princípios do DUA. Ao utilizar o DUA na elaboração e na aplicação das atividades, os autores identificaram que as estratégias promoveram o engajamento efetivo com o contexto educativo. Além disso, as atividades foram consideradas adequadas para todos os estudantes e não somente para os que têm TEA ou dificuldades de aprendizagem. Os resultados também demonstraram que são necessárias modificações no currículo para que este seja acessível a todos.

Roquejani (2018), aplicou os princípios do DUA no ensino de Geografia. A autora se embasou nessa perspectiva para realizar adequações curriculares e atividades para o ensino de cartografia. Dentre as atividades elaborou um material denominado "Cartografia para Todos" que apresentou situações de aprendizagem com adequações para uma sala inclusiva. Segundo a autora, as adequações realizadas enriqueceram as aulas, auxiliaram no planejamento em uma perspectiva inclusiva. Roquejani (2018) ainda destacou que as mudanças devem acontecer em todo ambiente escolar, bem como, as adequações curriculares com vistas no DUA podem favorecer a aprendizagem do aluno se considerar sua variabilidade e seu contexto de sala de aula.

Nessa última categoria, vimos que os autores se voltaram ao ato de propor o DUA como subsídio para a prática pedagógica inclusiva visando aplicar todos os seus princípios. Desse modo, promoveram o ensino direto destes princípios e aplicaram estratégias de aprendizagem, conforme a proposta do DUA. Por conseguinte, as pesquisas confirmam a aplicabilidade desta teoria, bem como, demostram os resultados qualitativos de sua implementação no contexto regular de ensino.

\section{Considerações finais}

A fim de tecer algumas considerações finais neste artigo, retomamos o problema de pesquisa: de que maneira a perspectiva do Desenho Universal 
para a Aprendizagem relacionada à inclusão educacional tem sido contemplada nas produções científicas brasileiras?

A partir da revisão sistemática, constatamos que nas 24 produções científicas analisadas, a perspectiva do DUA associado à inclusão educacional tem sido abordada nas pesquisas brasileiras no que diz respeito a elaboração de material didático, a formação docente inicial e/ou continuada, ao planejamento de ensino, a articulação com outro conceito e a prática pedagógica.

Destacamos que, para suprir lacunas com relação à formação docente para a inclusão de alunos com NEE e a prática pedagógica inclusiva, o DUA tem sido referenciado como uma perspectiva que evidencia princípios orientadores para promover e/ou aprimorar o processo de inclusão educacional. Nesse sentido, identificamos pesquisas atreladas a formação docente e ao planejamento de ensino que confirmam tal pressuposto que possibilitou conhecer a abordagem do DUA como conteúdo formativo no desenvolvimento profissional de professores para consolidação de uma educação inclusiva.

Percebemos que a implantação do DUA tem sido utilizado na produção de materiais didáticos na modalidade à distância e que sua utilização favorece a acessibilidade ao currículo, logo aos conteúdos que são trabalhados por meio das atividades e dos materiais de estudo.

Identificamos também produções científicas que implementaram a perspectiva na sala comum, as quais avaliamos ser um número pequeno para o contexto brasileiro signatário da implementação da educação inclusiva. No entanto, há uma carência de mais estudos que demostrem a implementação do DUA na prática pedagógica docente na classe comum apresentando como as atividades podem ser desenvolvidas visando atender as necessidades dos alunos com NEE e, ao mesmo tempo, possam ser realizadas pelos demais alunos sem NEE.

Consideramos que o DUA se constituiu numa proposta teórica recente, que, provavelmente, ainda é desconhecida por parte dos 
pesquisadores. Contudo, como vimos por meio das pesquisas já desenvolvidas e analisadas neste estudo, elas demonstram o potencial qualititativo dos princípios do DUA na prática pedagógica, visando satisfazer as necessidades de aprendizagem de todos os alunos.

Por fim, podemos afirmar que a pesquisa forneceu subsídios para caracterizar o cenário de abordagem da perspectiva do DUA nas produções brasileiras, bem como ofereceu elementos teóricos e práticos com relação as possibilidades de implementação do DUA no processo educativo, almejando uma prática pedagógica inclusiva. Desse modo, as pesquisas selecionadas nos apontam que o DUA redireciona o pensar reflexivo sobre a prática docente e instrumentaliza os professores para a organização da atividade de ensino e a elaboração de recursos didáticos mais acessíveis.

\section{Referências}

BASTOS, A. R. B. Proposição de recursos pedagógicos acessíveis: o ensino de Química e a tabela periódica. Journal of Research in Special Educational Needs, August 2016, v.16, p.923-927.

CALEGARI, E. P.; SILVA, R. S.; SILVA, R. P. Design instrucional e design universal para a aprendizagem: uma relação que visa obter melhorias na aprendizagem. Revista D.: Design, Educação, Sociedade e Sustentabilidade, v. 5, 2014

CAST. Design for Learning guidelines - Desenho Universal para a aprendizagem. CAST, 2011. (Universal version 2.0. - www.cast.org / www.udlcenter.org tradução).

CORREIA, S.; CORREIA, P. Acessibilidade e desenho universal. In: CORREIA, S.; CORREIA, P. Educação Especial: Diferenciação do Conceito à Prática. Porto: Gailivro, 2005. (Encontro Internacional).

COSTA, D. S. Diretrizes de qualidade para materiais educacionais no contexto da educação inclusiva. Dissertação de Mestrado (Programa de Pós-Graduação em Design). Porto Alegre, RS: Universidade Federal do Rio Grande do Sul, 2016.

CRUZ, M. M.; NASCIMENTO, F. F.. Acessibilidade ao currículo através do uso do computador para estudantes com autismo. Revista Artes de educar, v. 4, n. 1, 2018.

KRANZ, C. R. Os jogos com regras na educação matemática inclusiva. Dissertação de Mestrado (Programa de Pós-graduação em educação). Natal, RN: Universidade Federal do Rio Grande do Norte, 2011. 
LEMOS, E. S.; BERNARDI, G.; DAL-FORNO, J. P. Diretrizes de Acessibilidade para Deficientes Visuais no Moodle: Guia para Professores. Revista Rentote: Novas Tecnolgias na Educação, v. 14, v. 1, 2016.

LINDEMANN, R. H.; BASTOS, A. R. B.; ROMAN, B. Desenho Universal de Aprendizagem e Micro Ensino na Formação de Professores de Química. Revista de Ciência e Inovação, v. 2, n. 1, 2017.

MANTOAN, M. T. É. Inclusão escolar: O que é? Por quê? Como fazer? São Paulo: Summus, 2015.

MEYER, A.; ROSE, D.; GORDON, D. Desenho universal para a aprendizagem: Teoria e Prática. Wakefield, MA: ELENCO Professional Publishing, 2014.

MEYER, A.; ROSE, D.; GORDON, D. Universal Design for Learning (UDL). Estados Unidos: CAST, 2002.

NUNES, C.; MADUREIRA, I. Desenho Universal para a Aprendizagem: Construindo práticas pedagógicas inclusivas. Da Investigação às Práticas, v.5, n. 2, p. 126-143, 2015.

OMOTE, S. A formação do professor de educação especial na perspectiva da inclusão. In. BARBOSA, R.L.L. (Org.) Formação de educadores: desafios e perspectivas. São Paulo: UNESP, 2003. p. 153-169.

PACHECO, D. P. O ensino de ciências a partir do desenho universal para a aprendizagem: possibilidades para a educação de jovens e adultos. 220 p. 2017. Dissertação (Mestrado Profissional em Ensino de Ciências) - Universidade Federal do Pampa, Campus Bagé, Bagé, 2017.

PLETSCH, M. D.; SOUZA, F. F.; ORLEANS, L. F. A diferenciação curricular e o desenho universal na aprendizagem como princípios para a inclusão escolar. Revista Educação e Cultura Contemporânea, v. 14, n. 35, 2017.

PRAIS, J. L. S. Princípios do desenho universal para a aprendizagem: planejamento de atividades pedagógicas para inclusão. In: Anais do I Congresso Internacional de Ensino CONIEN, Cornélio Procópio, 2017 p. 452-469.

PRAIS, J. L. S. Formação inclusiva com licenciandas em Pedagogia: ações pedagógicas baseadas no Desenho Universal para a Aprendizagem. Dissertação de Mestrado (Programa de Pós-graduação em Ensino de Ciências Humanas, Sociais e da Natureza - PPGEN). Londrina, PR: Universidade Tecnológica Federal do Paraná, 2016.

PRAIS, J. L. S.; ROSA, V. F. Ação didática formativa para a inclusão: análise de um produto educacional. Revista de Produtos Educacionais e Pesquisas em Ensino, v. 1, n. $1,2017$. 
PRAIS, J. L. S.; ROSA, V. F. Formação Inicial de Professores para Inclusão: das Exigências aos Subsídios Teóricos e Práticos. Revista de Ensino, Educação e Ciências. Humanas, Londrina, v.17, número especial, Selitec - n. 15/16, p.440-447, 2016.

PRAIS, J. L. S.; ROSA, V. F. Princípios do Desenho Universal para a Aprendizagem: planejamento de atividades pedagógicas para inclusão. Revista Ideação, v. 18, n. 2, 2016.

RICARDO, D. C. Boas práticas de acessibilidade na Educação Superior: Tecnologia assistiva e desenho universal. Dissertação de mestrado (Programa de pósgraduação em educação). Juiz de Fora, MG: Universidade Federal de Juiz de Fora, 2017.

RICARDO, D. C.; SAÇO, L. F.; FERREIRA, E. L. F. O desenho universal na educação: novos olhares diante da inclusão do ser deficiente. Revista Iberoamericana de estudos em Educação, v.12, n. esp. 2, ago., 2017.

ROQUEJANI, T. C. O ensino de geografia com adequações curriculares em salas inclusivas do ensino fundamental - anos finais. Dissertação de mestrado (Programa de PósGraduação em Docência para a Educação Básica). Bauru, SP: Universidade Estadual Paulista "Júlio de Mesquita Filho" - Faculdade de Ciências, Campus de Bauru, 2018.

RODRIGUES, D. (Org.). Inclusão e educação: Doze olhares sobre a educação inclusiva. São Paulo: Summus, 2006.

SANTOS, C. E. R.. Ambiente Virtual de Aprendizagem e Cenários para investigação: contribuições para uma Educação Financeira acessível. Tese de Doutorado (Pós-Graduação em Educação Matemática). São Paulo: Universidade Anhanguera de São Paulo, 2016.

SANTOS, C. E. R.; FERNANDES, S. H. A. A. Um ambiente virtual interativo de aprendizagem para usuários com/sem limitações sensoriais. In: Anais do $V$ Congresso Internacional da Pró-Inclusão, 'Educação, Inclusão e Inovação, São Paulo, 2017.

SENRA, L. X.; LOURENÇO, L. M. A importância da revisão sistemática na pesquisa científica. In: BAPTISTA, M. N.; CAMPOS, D. C. Metodologias de pesquisas em Ciências: análises quantitativas e qualitativas. 2. ed. Rio de Janeira: LTC, 2016.

SONDERMANN, D. V. C. O design educacional para a modalidade a distância em uma perspectiva inclusiva: contribuições para/na formação docente. Tese de doutorado (Programa De Pós-Graduação Em Educação). Espírito Santo, ES: Universidade Federal do Espírito Santo, 2014.

TIZIOTO, S. A. O design universal na editoração de material didático como agente motivador e estimulador da autoeficácia para a aprendizagem. Dissertação de 
Mestrado (Programa de Pós-graduação em Engenharia de produção). São Carlos: Universidade de São Paulo, 2013.

VILARONGA, C. A. R.; MENDES, E. G. M.; ZERBATO, A. P. O trabalho em colaboração para apoio da inclusão escolar: da teoria à prática docente. Revista Interfaces da Educação, v. 7, n. 19, 2016.

ZERBATO, A. P. Desenho universal para aprendizagem na perspectiva da inclusão escolar: potencialidades e limites de uma formação colaborativa. Tese de Doutorado (Programa de Pós-Graduação em Educação Especial). São Carlos, SP: Universidade Federal de São Carlos, 2018.

ZERBATO, A. P.; MENDES, E. G. Desenho universal para a aprendizagem como estratégia de inclusão escolar. Revista Educação Unisinos, v. 22, n. 2, p. 147-155, abril-junho, 2018. 